\title{
USO DA ACUPUNTURA NA DOR
}

\author{
USE OF ACUPUNCTURE IN PAIN
}

\author{
Lopes, $\mathrm{MA}^{1}$, Cerutti, $\mathrm{ML}^{2}$, Valente, $\mathrm{C}^{3}$, Perusso, $\mathrm{E}^{4}$ \\ Afiliações: 1-Departamento de Farmácia da Universidade Regional de Blumenau - FURB. 2-Departamento de Medicina da Universidade \\ Regional de Blumenau - FURB. 3-Departamento de Ciências Naturais da Universidade Regional de Blumenau - FURB. 4-Departamento \\ de Ciências Biológicas da Universidade Tecnológica Federal do Paraná - UTFPR. \\ Endereço do autor de correspondência: Rua Augustinho Sbalqueiro, s/n, Loteamento Guizone, Verê, Paraná, Brasil. CEP: 85585-000. \\ edilaineperusso@hotmail.com.
}

\section{Resumo}

A acupuntura é considerado pela OMS como um método de tratamento complementar, introduzida pelo Ministério da Saúde através da Portaria GM nº 971, de 03 de maio de 2006. A acupuntura compreende a inter-relação do homem com o ambiente, através da teoria dos cinco elementos e das energias yin e yang. Seu objetivo é compreender os fatores que ocasionaram ao indivíduo o seu desequilíbrio energético e tentar restabelece-lo. A dor refere-se a uma experiência desagradável, sensorial e emocional, que tem a finalidade de proteger o corpo, que acaba comprometendo a qualidade de vida. A utilização da acupuntura no tratamento da dor ocorre através do estímulo no corpo causado pelas agulhas, fazendo que as substâncias responsáveis pela sensação de bem-estar, como endorfina e serotonina sejam liberadas, restabelecendo o equilíbrio e o funcionamento do corpo. A procura do alívio das dores é uma das razões para o crescente número de pesquisas sobre a acupuntura. $O$ presente estudo teve como objetivo reunir os dados existentes na literatura para compreender e demonstrar a utilização da acupuntura no tratamento da dor. Para isso, realizou-se uma revisão bibliográfica utilizando dados obtidos a partir da literatura disponível no PubMed, ScienceDirect e Google Acadêmico. Uma tabela foi elaborada utilizando 35 artigos publicados entre o período de 1998 a 2016, os quais demonstraram o efeito da acupuntura na dor. Concluiu-se que não há uma padronização no tratamento da acupuntura para dor, porém a mesma demonstrou-se eficaz na redução da dor e na melhora da qualidade de vida das pessoas.

Palavras-chave: MTC; Acupuntura; Dor; Fibromialgia.

\begin{abstract}
Acupuncture is considered by WHO as a method of complementary treatment, introduced by the Ministry of Health through Ordinance GM No. 971 of May 3, 2006. Acupuncture comprises the interrelation of man and the environment through the theory of five elements and energies yin and yang. Its goal is to understand the factors that caused the individual to their energy imbalance and try to reestablish it. Pain refers to an unpleasant, sensory and emotional experience that has the purpose of protecting the body, which ends up compromising the quality of life. The use of acupuncture to treat pain occurs through stimulation in the body caused by needles, causing substances responsible for the sensation of well-being, such as endorphin and serotonin to be released, restoring the body's balance and functioning. The search for pain relief is one of the reasons for the growing number of research on acupuncture. This study aimed to gather data from the literature to understand and demonstrate the use of acupuncture in pain management. For this, we performed a literature review using data obtained from the literature available in PubMed, ScienceDirect and Google Scholar. A table was prepared using 35 articles published between 1998 and 2016, which demonstrated the effect of acupuncture on pain. It was concluded that there is no standardization in the treatment of acupuncture for pain, but it has been shown to be effective in reducing pain and improving people's quality of life.
\end{abstract}

Keywords: Traditional Chinese Medicine; Acupuncture; Pain; Fibromyalgia. 


\section{Introdução}

A acupuntura, prática que faz parte da MTC, é uma técnica milenar que surgiu na China antes de Cristo. Essa prática baseia-se na ideia de que o indivíduo é constituído por uma energia, a qual flui por todo o corpo através dos meridianos. Quando esta energia está em desarmonia surgem então as doenças. A acupuntura visa estabelecer a fluidez energética obtendo o equilíbrio através da estimulação de acupontos, também conhecidos como pontos de acupuntura, os quais estão localizados ao longo dos meridianos de nosso corpo.

A dor possui uma função importantíssima no organismo dos indivíduos: alertar quando algo de errado estiver acontecendo. Ela tem o objetivo de estimular os nociceptores que são os receptores da dor. Os estímulos podem ser mecânicos, térmicos ou químicos. Neste contexto, ela desencadeia a doença propriamente dita, ou seja, não se trata mais de ser apenas um aviso de outra enfermidade. A dor possui diversos sentidos, mas sempre está relacionada ao sofrimento e possui uma alta prevalência, causando diversos impactos aos indivíduos portadores, aos seus familiares, ao sistema de saúde e à economia do país. Além disso, ela está fortemente relacionada aos casos de aposentadoria precoce e desemprego, se tornando um grave problema de saúde pública. Os indivíduos portadores de dor podem apresentar vários outros sintomas ou distúrbios, como por exemplo, depressão, ansiedade, alterações do sono, problemas nutricionais, dependência medicamentosa, dependência alcoólica, frustração. Além disso, ela interfere na qualidade de vida e no bemestar, bem como limitando as atividades do dia a dia em geral. Dentro do quadro de dor podemos citar a fibromialgia, uma síndrome de origem não inflamatória que se manifesta com quadro de dor generalizada no sistema musculoesquelético.

Em geral, a dor possui maior prevalência no sexo feminino e sua importância pode ser notada pela elevada incidência de artigos e reportagens realizadas sobre o tema. Estima-se que a dor afeta cerca de $30 \%$ da toda a população mundial. No Brasil sua incidência varia de $15 \%$ a $40 \%$, dependendo de cada estado, e é um dos principais motivos que levam as pessoas a procurar atendimento ambulatorial. O objetivo da acupuntura é prevenir e tratar as desarmonias energéticas, melhorando assim a dor. A acupuntura, através dos 
estímulos realizados pelas agulhas, promove a

liberação de algumas substâncias como a endorfina e serotonina que agem na modulação da dor. Além disso, o baixo custo dos materiais, a facilidade de aplicação e manuseio desta técnica e a escassez dos efeitos colaterais demonstram que a acupuntura é uma técnica vantajosa para esse tipo de tratamento.

$\mathrm{O}$ interesse cientifico pela acupuntura evoluiu muito nos últimos, já que ela tem sido utilizada como tratamento terapêutico coadjuvante. Suas bases neurofisiológicas na analgesia já são conhecidas, porém há um amplo caminho a se pesquisar, visto que o tratamento através da acupuntura vai além da "simples" colocação de agulhas. Os estudos realizados com intuito de comprovar a eficácia da acupuntura são prejudicados pela falta de padronização, classificação e comparação entre os estudos já existentes, que muitas vezes são inconclusivos com relação à sua eficácia. Neste sentido, oobjetivo do trabalho é reunir dados existentes na literatura para compreender e elucidar a utilização da acupuntura no tratamento da dor.

\section{Métodos}

O presente trabalho foi baseado em uma revisão bibliográfica na qual foram utilizados dados obtidos a partir da literatura disponível. Para a realização da coleta de dados foram utilizados livros, artigos, trabalhos de conclusão de curso, revistas, dissertações e teses relacionadas à Acupuntura e Dor. Os artigos foram pesquisados nos bancos de dados do PubMed, ScienceDirect e Google Acadêmico, compreendidos no período de 1995 até 2016 totalizando 35 artigos. Apesar de a acupuntura ser uma ciência milenar, esse tema é muito nova aqui no ocidente e com pouco conteúdo atual, por isso também foram utilizados dados mais antigos.

O material pesquisado foi lido e seu conteúdo foi interpretado, discutido e resumido em uma tabela com os dados dos pontos de acupuntura utilizados, número e idade dos participantes, tempo de tratamento, número de sessões e conclusão do tratamento. 


\section{Desenvolvimento}

\section{MEDICINA TRADICIONAL CHINESA}

(MTC)

A Medicina Tradicional Chinesa (MTC) é uma ciência milenar surgida na China antes de Cristo, essa prática não está voltada para a doença, mas sim aos fatores causadores da doença, as diversas maneiras de tratá-la e como preveni-la ${ }^{1}$. Dentro da MTC existem diversos conceitos, dentre eles: Conceito Yin/Yang, Energia Qi, Teoria dos Cinco Elementos e Conceito Zang Fu ${ }^{1}$.

As observações iniciais feitas na China antiga notaram que a estrutura básica do ser humano e do universo é a mesma. Sendo assim, classificaram os fenômenos em dois polos opostos: Yin e Yang 1; 2; 3 . O conceito Yin/Yang (Figura 1) refere-se às forças contrárias, as quais se completam e são dependentes uma da outra. Enquanto Yin está voltado à escuridão, representado pelo lado negro, Yang representa a claridade, representado pelo lado branco. A teoria Yin/Yang segue o princípio da dualidade, o qual o positivo necessita do negativo e vice e versa ${ }^{1 ;}$

$2 ; 3$.

Figura 1 - Teoria Yin-Yang

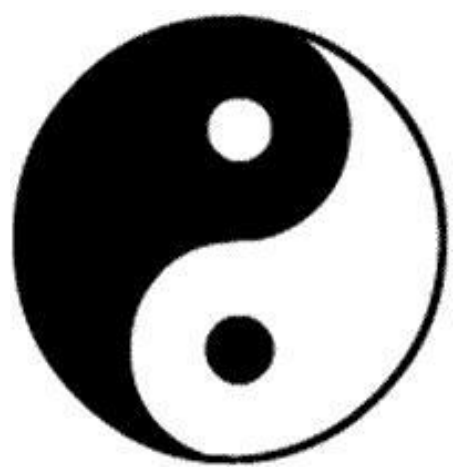

Fonte: Wu (2010, p. 26)

Além disso, a MTC acredita que existe uma suposta "energia" chamada de Qi (chi) conhecida como a energia vital a qual pertence a todas as coisas e flui ao longo de todo o corpo. A energia Qi possui diversas funções, dentre elas a de transformação, transporte, manutenção, ascendência, proteção, controle e aquecimento $1 ; 3 ; 4$. Essa energia equilibra as forças opostas Yin e Yang, sendo assim, quando essas forças estão em equilíbrio essa energia flui livremente, porém quando há uma obstrução dessa energia ocorre um desequilibrio e então surge a doença ${ }^{5}$. O 
autor Yamamura $^{1}$ relata que diversos

fatores podem ocasionar esse desequilíbrio,

como por exemplo, alimentação irregular, emoções aprisionadas, meio ambiente, fadiga, traumas, entre outros.

A Teoria dos Cinco Elementos ou dos Cinco Movimentos está baseada nos elementos Água, Fogo, Terra, Madeira e Metal (Figura 2) os quais estão relacionados às funções fisiológicas do corpo e dos órgãos, aos aspectos mentais e condições de adoecimento ${ }^{6 ;}$. O organismo vivo e o universo possuem o mesmo princípio, desta maneira, as atividades fisiológicas podem sofrer influência da natureza. Neste contexto, foi possível classificar os cinco elementos na natureza e no corpo humano. Esses elementos possuem uma relação de movimentação constante, simbolizando assim uma movimentação energética. A água rega a planta que brota e cresce formando a madeira. A madeira nutre o fogo através de sua queima e as cinzas geradas depositadas no solo alimentam a terra, que em seu interior gera vários metais e a água nasce das fontes minerais $6 ; 8$.

Algumas das técnicas utilizadas dentro da MTC são: Acupuntura, Auriculoterapia,
Moxabustão, Sangria, Eletroacupuntura, Laser, Ventosaterapia, Fitoterapia Chinesa, Gua-Sha, Craniopuntura de Yamamoto, Tuiná, Do In, Tai Chi Chuan e Qi Chong ${ }^{1 ;} 4$.

Figura 2 - Teoria dos Cinco

Elementos

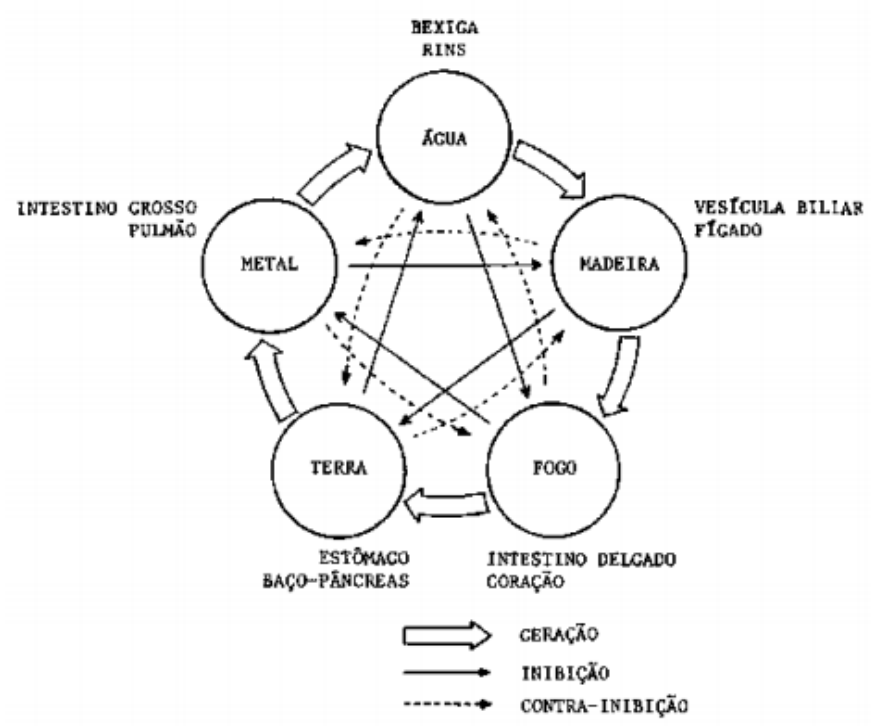

Fonte: Wen (1985 p. 22)

\section{ACUPUNTURA}

A acupuntura palavra que deriva do latim acum, que significa agulha, e punctum que significa picada é o pilar principal da MTC. Essa técnica é utilizada desde 3.000 anos antes de Cristo para se obter efeitos terapêuticos e ou analgésicos através da inserção de agulhas nos pontos anatômicos específicos do corpo, os 
quais possuem uma elevada concentração de terminações nervosas sensoriais $9 ; 10$.

Os pontos de acupuntura estão localizados por toda a superfície do corpo e apresentam maior condutibilidade elétrica devido a uma maior densidade das gap junctions de suas células, além de apresentarem um aumento nas taxas metabólicas, temperatura e concentração de cálcio intracelular. Esses pontos anatômicos específicos também conhecidos como acupontos, são considerados pela MTC como a área mais exterior do corpo energético, servindo como um elo de comunicação entre o meio externo e interno. Os pontos de acupuntura possuem locais e funções definidas os quais são responsáveis pela resposta às doenças, são dolorosos e sensíveis a pressão e estão situados ao longo dos meridianos. Ao estimular esses pontos, alguns neurotransmissores e hormônios como serotonina, adrenalina e cortisol podem ser liberados ocasionando a analgesia ${ }^{3 ; 9}$.

Existem várias formas de estimular os pontos de acupuntura, dentre elas as agulhas (acupuntura e auriculoterapia), digitopressão (Do In), eletroacupuntura (estímulo elétrico), moxabustão (queima da erva Artemísia vulgaris) e laser ${ }^{1 ; 4}$.

A acupuntura não visa tratar apenas o local lesionado ou aos agentes agressores, mas busca principalmente estimular os mecanismos de compensação, agindo no Sistema Nervoso Central (SNC) para restabelecer o equilíbrio do corpo como um todo ${ }^{2}$. Além disso, esta estimulação pode alterar a circulação sanguínea e favorecer o relaxamento da musculatura, bem como diminuir a inflamação e a dor ${ }^{11}$ Segundo Hwang ${ }^{12}$, alguns estudos morfofuncionais apontaram que os prováveis receptores dos acupontos seriam os plexos nervosos, elementos vasculares e feixes musculares. Nesses acupontos também foram observadas junções específicas de mastócitos e células nervosas, sendo que após a estimulação desses pontos através de agulha também foi observado a degranulação de mastócitos. Os mastócitos estão associados às reações de hipersensibilidade imediata, inflamação e doenças parasitárias ${ }^{11}$.

$\mathrm{O}$ autor $\mathrm{Wen}^{2}$ relata que a acupuntura possui diversos mecanismos diferentes de ação, dentre eles: 
1) Modifica a circulação sanguínea através de microdilatações e causa o relaxamento muscular, melhorando a inflamação e o processo doloroso;

2) Libera hormônios;

3) Eleva os mecanismos de resistência;

4) Regulariza as funções orgânicas, tornando a recuperação mais rápida;

5) Recupera o metabolismo quando o mesmo é afetado por uma determinada doença.

A acupuntura é muito eficaz para o tratamento de doenças, pois apresenta efeito analgésico, sendo ele por meio do sistema de modulação ascendente e descendente ou por meio de outros mecanismos que favorecem o bem estar ${ }^{13}$. Essa analgesia acontece devido a liberando de opióides endógenos que promovem um alívio da dor ${ }^{14}$. Apesar de grande parte dos estudos avaliarem o efeito da acupuntura na dor, o principal objetivo da MTC é a prevenção, manutenção e tratamento das desarmonias energéticas e da saúde. Sendo assim, a atenuação da dor refere-se a uma função secundária do tratamento ${ }^{15}$.

No Brasil, a acupuntura foi inserida em 1999 na tabela do Sistema de Informação Ambulatorial - SIA/SUS através da Portaria ${ }^{\circ}$
1230/GM. Em 2006 ela foi reforçada através da Portaria nº 971 do Ministério da Saúde, a qual aprovou a Política Nacional de Práticas Integrativas e Complementares no Sistema Único de Saúde - PNPIC/SUS.

\section{DOR}

A dor pode ser rápida ou lenta e acontece sempre que há uma lesão tecidual, atuando como um mecanismo de proteção o qual alerta o indivíduo a retirar o estímulo doloroso. A dor rápida, também conhecida como dor aguda ou dor pontual, é aquela que ocorre em até 0,1 segundo após um estímulo, enquanto a dor lenta, também chamada de dor crônica ou dor persistente, é aquela que ocorre após um segundo após um estímulo ${ }^{16}$.

Ela faz parte de um sistema de fuga primitivo que teria como função levar o organismo a escapar de eventos nocivos. Ela prepara o organismo para cuidar de uma lesão, evitar maiores lesões e o perigo de infecção dos tecidos lesados ${ }^{17}$. A dor acontece quando ocorre uma ativação das redes neurais ligadas a uma passividade e 
proteção do organismo, a qual essa passividade defensiva permite que a lesão cure. Porém se essa passividade prolongase por muito tempo, ela acaba sensibilizando os tecidos.

A dor aguda é considerada um sintoma que serve como "alerta" nos casos de lesões ao organismo, ou seja, ela é essencial para prevenir a integridade do mesmo, pois alertará quando houver algum problema. Já a dor crônica não possui esse mesmo valor biológico e para os profissionais de saúde, é um dos problemas mais dificultosos de controlar ${ }^{18}$. Ela é definida como uma dor contínua ou recorrente que persiste por no mínimo três meses. Geralmente ela não desaparece com os tratamentos convencionais e gera incapacidade e inabilidade prolongada ${ }^{19}$.

A dor é compreendida de formas diferentes pela medicina ocidental e pela medicina oriental. Enquanto a medicina ocidental relata que a dor apresenta-se como uma desagradável sensação, podendo causar um incomodo leve ou excruciante devido a uma lesão atual ou potencial no organismo, a medicina oriental explica a dor como sendo uma estagnação da energia Qi devido a um desequilíbrio ${ }^{20}$.

De acordo com o autor Yamamura ${ }^{21}$, a MTC classifica a dor de acordo com os fatores energéticos envolvidos, podendo ser eles:

- Fator Yang: Dor aguda localizada, de grande intensidade em forma de pontada, causando sensação de choque elétrico ou cólica;

- Fator Falso Yang: Dor em forma de queimação e ardência (dor interposta entre Yin e Yang), causada pela deficiência de Yin Qi;

- Fator Yin: Dor constante e insidiosa, de localização inespecífica, superficial e interna com sensação de sobrecarga e aperto, causada pela influência de Frio e Umidade.

Os indivíduos com quadro de dor crônica são os que mais procuram o tratamento através da acupuntura ${ }^{22}$. 
Fisiologia da dor

As terminações nervosas localizadas na superfície da pele e em alguns tecidos internos servem como receptores aos estímulos dolorosos. Esses receptores podem ser estimulados por três diferentes estímulos, sendo eles: estímulos químicos, térmicos e mecânicos. A dor aguda ou pontual é desenvolvida por estímulos térmicos ou mecânicos que são transmitidos através das fibras A-delta nos nervos periféricos até a medula espinhal. A dor crônica ou persistente é desencadeada na maioria das vezes pelos estímulos químicos, porém os estímulos térmicos e mecânicos incessantes também podem desencadear a dor. Este estímulo é transmitido pelas fibras C até a medula. Quando há uma infecção, trauma, lesão, ou algum outro fator, as terminações nervosas existentes no local afetado enviam estímulos dolorosos através dos nervos até a medula espinhal ${ }^{23}$. Na medula espinhal, os estímulos são enviados ao cérebro através de duas vias distintas conhecidas como Trato Neoespinotalâmico para dor rápida que envia os sinais das fibras A-delta, e Trato Paleoespinotalâmico para dor crônica que envia os sinais das fibras $\mathrm{C}$, porém também pode transmitir sinais das fibras A-delta ${ }^{16}$. Chegando ao cérebro, esses estímulos sinalizam a dor, e então o mesmo emite respostas a este estímulo ${ }^{17 ; 23}$. Esta atividade é regulada por substâncias geradas no sistema nervoso, como por exemplo, a serotonina e a endorfina que agem na transmissão da dor, podendo aumentar ou diminuir essa sensação dolorosa. Esse mecanismo é conhecido como Sistema Modulador de Dor (Figura 3) ${ }^{24}$.

A localização de um ponto específico na dor crônica é dificultada pela conectividade multissimpática difusa da via paleoespinotalâmica. Neste contexto, a dor é identificada em uma determinada região, como por exemplo, o braço, mas não é possível identificar-se o ponto específico da dor. Por este motivo os pacientes têm dificuldades em apontar o local exato da dor em uma determinada região ${ }^{16}$. 
Figura 3 - Via de Modulação da Dor

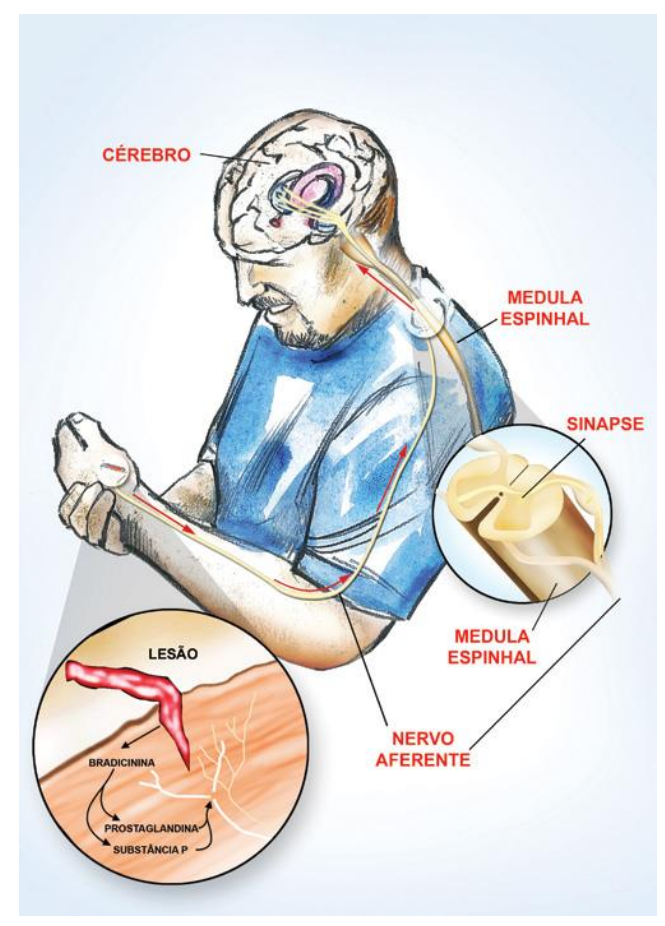

Autor: Bandeira (2012)

O Sistema de Supressão da Dor, também conhecido como Sistema de Analgesia é responsável pelo controle da dor, sendo que o grau de dor sentido varia de indivíduo para indivíduo devido à capacidade do encéfalo em abolir os sinais dolorosos para o sistema nervoso, estimulando o Sistema de Supressão da Dor. A encefalina e a serotonina são os principais neurotransmissores envolvidos nesse sistema. Dificilmente esses receptores se adaptam aos estímulos, pois isso possibilita a percepção da presença do estímulo enquanto a dor perdurar. O grau de dor varia de acordo com o grau de lesão tecidual e a hiperalgesia ocorre quando há uma elevada sensibilidade à dor, ocorrendo uma hipersensibilidade dos seus receptores ou quando ocorre uma facilitação da transmissão sensorial ${ }^{16}$.

Os autores Guyton; Hall ${ }^{16}$ relatam a descoberta de que é possível reduzir os sinais de dor oriundos do mesmo local quando há estimulação dos receptores táteis periféricos das fibras sensoriais A-delta. O autor salienta que este mecanismo acompanhado da estimulação do sistema de analgesia são os possíveis fundamentos da acupuntura. Embora existam diversos tipos de tratamento para dor, muitas pessoas encontram-se insatisfeitas com os resultados obtidos pela medicina tradicional 25 .

\section{FIBROMIALGIA}

A fibromialgia caracteriza-se por uma dor músculo-esquelética disseminada com diversos pontos dolorosos, que persiste por mais de três meses. Frequentemente a fibromialgia está associada à rigidez, 
fadiga, alterações no sono, depressão e ansiedade $^{26}$. O American College of Rheumatology determinou os seguintes critérios para diagnosticar a fibromialgia: dor generalizada por mais de três meses, que atinge ambos os lados e também as partes superiores e inferiores à cintura, presença de dor axial, com no mínimo 11 de um total de 18 tender points (Figura 4) apresentando sensibilidade a dor com aproximadamente $4 \mathrm{~kg}$ de pressão (Figura 5) 27 .

Figura 4 - Tender points

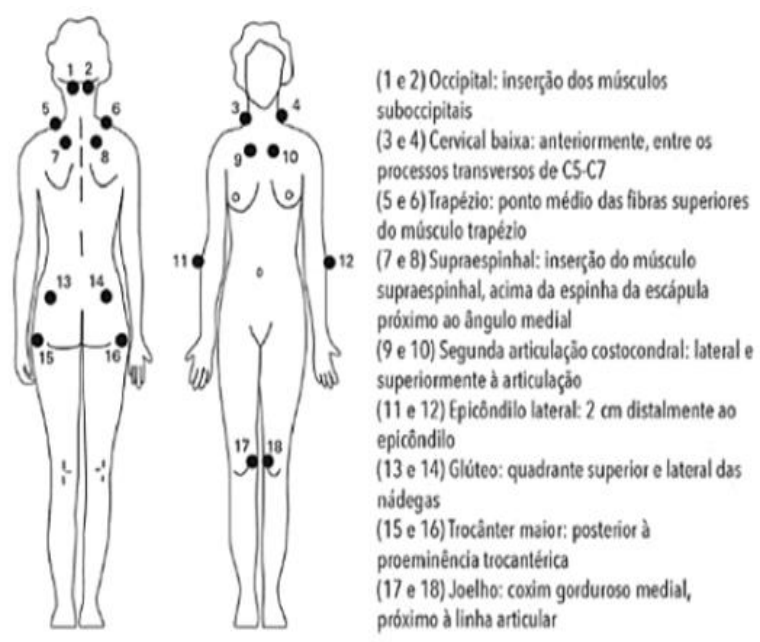

Fonte: Okifuji et al., (1997).
Figura 5 - Diagnóstico de

Fibromialgia

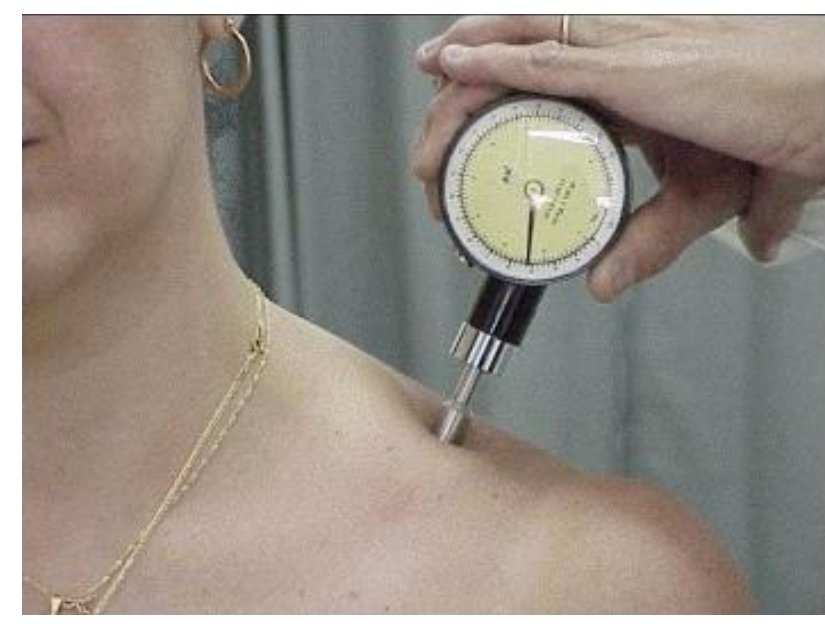

Fonte: Fischer (1988).

A fibromialgia é examinada e tratada por um reumatologista devido ao quadro de dor musculoesquelética crônica, porém é muito comum os pacientes buscarem um acompanhamento de outras áreas para obter um melhor e mais completo resultado. A Sociedade Brasileira de Reumatologia publicou em 2004 as diretrizes iniciais a respeito da fibromialgia, cujo propósito é o direcionamento ao diagnóstico e tratamento da mesma ${ }^{28}$.

Acredita-se que sua patogênese esteja relacionada a um distúrbio na modulação central da dor ou então a uma alteração no SNC devido à resposta de 
estímulos nociceptivos, porém sua patogênese ainda não é muito esclarecida ${ }^{29}$; 30. A maioria dos pacientes com fibromialgia são sedentários e essa alteração do metabolismo pode estar relacionada ao aumento da sensibilidade à dor nesses pacientes devido à redução do condicionamento físico ${ }^{31}$.

Indivíduos portadores de fibromialgia possuem alterações no processo de dor pelo SNC e periférico através de uma propagação elevada da dor, podendo ser causada inicialmente por algum fator periférico, como por exemplo, uma lesão ou uma inflamação ${ }^{32}$.

Estima-se que a fibromialgia atinja cerca de 2,5\% da população brasileira, com maior predomínio em mulheres e com idades entre 45 e 64 anos ${ }^{33}$. Existem diversos trabalhos publicados que investigaram alterações nas estruturas e nas funções do cérebro associadas à sensibilização central, os quais evidenciaram uma diminuição da massa cinzenta nas áreas relacionadas à dor, enquanto que a massa cinzenta global não apresentava diminuição ${ }^{34}$. Pessoas que possuem fibromialgia apresentam um limiar menor de dor e uma resposta elevada das áreas geradoras de dor ${ }^{35}$.

Um estudo publicado no Jornal de Terapia Manual, Posturologia \& Reabilitação demonstrou que a acupuntura é eficaz no controle da dor e do sono, além de contribuir na qualidade de vida de pessoas portadoras de fibromialgia ${ }^{36}$. Outro estudo publicado na revista Movimenta relata que a eficácia da acupuntura na fibromialgia é controversa, pois existem estudos que demonstram a eficácia e outros não ${ }^{37}$.

\section{Fibromialgia pela MTC}

Existem três estruturas que estão diretamente relacionadas à fibromialgia: Cou Li (localizado entre a pele e o músculo), Luo (canais de conexão) e Jing Jin (canais musculares). Quando determinados fatores externos, como por 
exemplo, o frio, o vento e a umidade atingem essas estruturas, obtém-se o quadro de fibromialgia pela obstrução da energia Qi e do sangue ${ }^{38}$. Um estudo concluiu que a acupuntura eleva os níveis de endorfina e serotonina, bem como o fluxo sanguíneo nos tender points ${ }^{39}$.

Tratamento pela Medicina Ocidental

O tratamento medicamentoso pode ser realizado através de bloqueadores neuromusculares, compostos tricíclicos, analgésicos, neuromediadores, medicamentos para depressão, inibidores da recaptação da serotonina, medicamentos para enjoo/náuseas/vômito, fármacos que induzem ao sono e medicamentos utilizados na doença de Parkinson ${ }^{28}$.

\section{CONTRAINDICAÇÃO}

A acupuntura é contraindicada durante a gravidez, em dermatites, áreas tumorais e em pessoas portadoras de marcapasso $^{40}$.

\section{Discussão}

Por tratar-se de um tema com muitas divergências e sem uma padronização é importante ressaltarmos que foi levantado uma grande quantidade de artigos disponíveis sobre a utilização da acupuntura na dor.

O estudo será apresentado em duas tabelas (tabela 1 e tabela 2) que abordam a eficácia de diversas formas de utilização da acupuntura no tratamento da dor. A tabela 1 é composta por 15 pesquisas que demonstraram o efeito da acupuntura nas dores em geral e a tabela 2 é composta por 20 pesquisas as quais demonstraram o efeito da acupuntura na fibromialgia.

Algumas variáveis de primeira ordem importantíssimas como número de pacientes, sexo, idade, pontos utilizados, quantidade e tempo das sessões os quais são determinantes para os resultados foram por 
diversas vezes resumidas ou nem sequer mencionadas nesses estudos.

Muitos trabalhos possuem grupos placebo e/ou acupuntura sham. O termo placebo também é conhecido como controle negativo, pois neste caso as agulhas não são inseridas e serve para descartar efeitos fisiológicos adversos. A acupuntura sham é conhecida como "falsa acupuntura", pois neste caso os pacientes acreditam que estão recebendo o tratamento, porém as agulhas são inseridas em outros locais que não sejam os pontos de acupuntura ou então são utilizadas agulhas que parecem estar penetrando a pele, mas isso não ocorre de fato $^{41}$.

Dentre as diversas pesquisas realizadas sobre a utilização da acupuntura nas dores em geral, os seguintes resultados foram encontrados:

Barcelos et $\mathrm{al}^{42}$ compararam a técnica de acupuntura e o alongamento para a dor lombar crônica e concluíram que ambos os tratamentos foram eficazes, porém a acupuntura demonstrou um efeito mais rápido.

Borin et $\mathrm{al}^{43}$ demonstraram a eficácia da acupuntura nas desordem temporomandibulares em comparação ao grupo placebo.

Leibing et $\mathrm{al}^{44}$ evidenciaram que a acupuntura foi eficaz na lombalgia crônica quando comparada aos cuidados de rotina, mas não em comparação com o grupo de acupuntura sham.

Thomas et $\mathrm{al}^{45}$ concluíram que houve uma baixa evidência sobre efeito da acupuntura na dor lombar persistente aos 12 meses e uma maior evidência de um pequeno benefício em 24 meses.

Inoue et $\mathrm{al}^{46}$ relataram que ambos os tratamentos com anestésicos e com acupuntura na dor lombar obtiveram eficácia no alivio da dor, porém a acupuntura foi superior nos efeitos imediatos, se tornando um tratamento mais útil.

Brinkhaus et al ${ }^{47}$ observaram que a acupuntura foi eficaz em comparação com 
o grupo placebo que não recebeu nenhum tratamento, porém não evidenciou-se diferenças entre acupuntura e a acupuntura sham.

A autora Parisotto ${ }^{48}$ comparou os resultados nos três grupos: Acupuntura, acupuntura sham e placebo na dor muscular tardia e na capacidade de contração muscular e concluiu que a acupuntura foi eficaz com relação aos demais grupos.

Carvalho et $\mathrm{al}^{49}$ ambos os tratamentos de acupuntura e auriculoterapia foram eficazes na dor lombar, porém a acupuntura sistêmica foi mais eficaz.

Os trabalhos desenvolvidos pelos autores $50 ; 51 ; 52 ; 53 ; 54 ; 55 ; 56$ demonstraram a eficácia da acupuntura em algumas diversas dores porém sem a comparação com outras técnicas.

Dentre as diversas pesquisas realizadas sobre a utilização da acupuntura na fibromialgia, os seguintes resultados foram encontrados:

Stival et $\mathrm{al}^{57}$ compararam os resultados obtidos com apenas uma sessão realizada nos dois grupos, acupuntura e placebo, e observaram um efeito bastante significativo no grupo tratado com a acupuntura.

Takiguchil et $\mathrm{al}^{58}$ fizeram a comparação da utilização da acupuntura tradicional e da acupuntura nos tender points e concluíram que ambas foram eficazes, porém a acupuntura aplicada nos tender points mostrou-se mais eficaz.

Vas et $\mathrm{al}^{59}$ demonstraram a eficácia da acupuntura em comparação a acupuntura sham nos 153 pacientes participantes da pesquisa.

Hadianfard; Parizi ${ }^{60}$ concluíram que a acupuntura foi mais eficaz no tratamento do que o medicamento Fluoxetina, além disso, relataram que a acupuntura não apresentou nenhum efeito colateral.

Harris et $a^{61}$ concluíram que a acupuntura foi eficaz no tratamento, porém a correta localização da agulha e sua estimulação não foram cruciais na eficácia do tratamento. Assefi ${ }^{62}$ observaram que o tratamento através da acupuntura não foi 
mais eficaz do que a acupuntura sham na diminuição da dor, porém ${ }^{63}$ concluíram que acupuntura foi mais eficaz do que a acupuntura sham na redução da dor.

O autor Dias ${ }^{64}$ concluiu que nenhum dos três métodos de tratamento: acupuntura, eletroacupuntura e moxabustão utilizados no estudo promoveram uma diminuição da dor nas pacientes participantes.

Vas et $\mathrm{al}^{65}$ não haviam concluído a pesquisa pois os resultados obtidos seriam analisados em 10 semanas, 6 meses e 12 meses a partir do início do tratamento.

Martin et al $^{66}$ concluíram que a acupuntura foi eficaz na melhora da dor, da fadiga e da ansiedade nos pacientes com fibromialgia.

Targino et $\mathrm{al}^{67}$ observaram que ao final das 20 sessões, os pacientes que receberam acupuntura tiveram uma significante melhora no quadro da dor em comparação ao grupo controle.

Araujo $^{68}$ concluiu que a acupuntura reduziu a intensidade da dor, o número de pontos dolorosos e o índice miálgico dos pacientes com fibromialgia.

Os autores $69 ; 70 ; 71 ; 72 ; 73 ; 74 ; 75 ; 76$ demonstraram a eficácia da acupuntura na fibromialgia, porém sem a comparação com outras técnicas.

Alguns pacientes que receberam a acupuntura nos tender points ou não-pontos de acupuntura, também obtiveram uma melhora no quadro de dor. Essa melhora pode ser ocasionada pela lesão que ocorre no local propriamente dito pela agulha, agilizando o processo de recuperação do tecido ${ }^{77}$. Os autores Saidah et $\mathrm{al}^{22}$ relatam que os microtraumas causados pela inserção da agulha promovem respostas inflamatórias, imunológicas e vaso dilatação que alteram o tônus muscular.

Christ $^{78}$ demonstrou em seu estudo que a maioria dos pacientes possui uma diminuição da dor já nas primeiras sessões, porém alguns pacientes precisam de um tratamento mais prolongado para obter um melhor resultado. Sendo assim, a 
quantidade de sessões é um fator importantíssimo a se levar em conta.

A utilização da acupuntura na dor não apresenta apenas efeito analgésico, ela também possui efeito semelhante ao dos anti-inflamatórios, pois acaba ocasionando uma diminuição do exsudato através da inibição da permeabilidade vascular a qual limita a aderência leucocitária ${ }^{79 ; 80}$. 
TABELA 1. Estudos da literatura com o uso da Acupuntura nas dores em geral.

\begin{tabular}{|c|c|c|c|c|c|c|c|c|c|c|}
\hline ITEM & TÍTULO & COMPARAÇÃO & PACIENTES & SEXO & IDADE & PONTOS & SESSÕES & TEMPO & CONCLUSÃO & REFERÊNCIA \\
\hline 1 & $\begin{array}{c}\text { Acupuntura e } \\
\text { alongamento no } \\
\text { tratamento da dor } \\
\text { lombar crônica. } \\
\text { Estudo } \\
\text { comparativo }\end{array}$ & $\begin{array}{l}\text { Acupuntura } \mathrm{x} \\
\text { Alongamento }\end{array}$ & 20 pacientes & $\begin{array}{c}2 \\
\text { homens } \\
\text { e } \\
8 \\
\text { mulheres }\end{array}$ & $\begin{array}{l}55 \text { à } 70 \\
\text { anos }\end{array}$ & Não relata & $\begin{array}{l}10 \text { sessões } \\
\quad(2 x \\
\text { semana) }\end{array}$ & $\begin{array}{l}\text { Não } \\
\text { relata }\end{array}$ & $\begin{array}{c}\text { Os dois } \\
\text { tratamentos } \\
\text { foram } \\
\text { igualmente } \\
\text { eficazes, porém } \\
\text { a acupuntura } \\
\text { demonstrou um } \\
\text { alívio mais } \\
\text { rápido. }\end{array}$ & $\begin{array}{l}\text { BARCELOS et al., } \\
2007\end{array}$ \\
\hline 2 & $\begin{array}{c}\text { Acupuntura na } \\
\text { síndrome do túnel } \\
\text { do carpo: Relato de } \\
\text { um caso }\end{array}$ & Acupuntura & 1 paciente & $\begin{array}{l}\text { Não } \\
\text { relata }\end{array}$ & 42 anos & $\begin{array}{c}\text { CS7, CS8, P10 } \\
\text { e C7 } \\
\text { unilateralmente } \\
\text { e IG4, B60 e } \\
\text { VB34 } \\
\text { bilateralmente }\end{array}$ & 6 sessões & $\begin{array}{c}20 \\
\text { minutos }\end{array}$ & $\begin{array}{l}\text { A acupuntura } \\
\text { demonstrou-se } \\
\text { eficaz ao } \\
\text { tratamento. }\end{array}$ & BARBOSA, 2007 \\
\hline 3 & $\begin{array}{c}\text { Efeito da } \\
\text { acupuntura em } \\
\text { adultos com } \\
\text { disfunção } \\
\text { temporomandibular }\end{array}$ & Acupuntura & 20 pacientes & \begin{tabular}{l}
\multicolumn{2}{c}{5} \\
homens \\
e 15 \\
mulheres
\end{tabular} & $\begin{array}{l}16 \text { à } 67 \\
\text { anos } \\
\text { (média } \\
44)\end{array}$ & Não relata & $\begin{array}{c}4 \text { à } 10 \\
\text { sessões } \\
\text { (média de } \\
6 \text { ) }\end{array}$ & $\begin{array}{c}20 \\
\text { minutos }\end{array}$ & $\begin{array}{l}\text { A acupuntura } \\
\text { demonstrou-se } \\
\text { eficaz ao } \\
\text { tratamento. }\end{array}$ & $\begin{array}{l}\text { SOUSA et al., } \\
2014\end{array}$ \\
\hline 4 & $\begin{array}{l}\text { Acupuntura no } \\
\text { Tratamento de } \\
\text { Bursite no Ombro }\end{array}$ & Acupuntura & 2 pacientes & $\begin{array}{l}\text { Não } \\
\text { relata }\end{array}$ & 66 anos & $\begin{array}{l}\text { IG4, ID12, } \\
\text { ID14, VG20, } \\
\text { VB13, ID8, } \\
\text { IG11, C5, C7, } \\
\text { Pontos Ashi, } \\
\text { Ponto Extra } \\
\text { (A), Moxa no } \\
\text { local da dor. }\end{array}$ & $\begin{array}{l}1 \text { mês } \\
(1 \mathrm{x} \\
\text { semana) }\end{array}$ & $\begin{array}{l}\text { Não } \\
\text { relata }\end{array}$ & $\begin{array}{l}\text { A acupuntura } \\
\text { demonstrou-se } \\
\text { eficaz ao } \\
\text { tratamento em } \\
\text { ambos os casos. }\end{array}$ & $\begin{array}{l}\text { FURLANETO E } \\
\text { ALCARDE, } 2016\end{array}$ \\
\hline
\end{tabular}




\begin{tabular}{|c|c|c|c|c|c|c|c|c|c|c|}
\hline & & & & $\begin{array}{l}\text { Não } \\
\text { relata }\end{array}$ & 67 anos & $\begin{array}{l}\text { ID12, ID13, } \\
\text { ID14, C2, IG4, } \\
\text { VG20, Pontos } \\
\text { Ashi, Pontos } \\
\text { Extra (A), } \\
\text { Yintang. }\end{array}$ & $\begin{array}{l}2 \text { meses } \\
(1 \mathrm{x} \\
\text { semana })\end{array}$ & $\begin{array}{l}\text { Não } \\
\text { relata }\end{array}$ & & \\
\hline 5 & $\begin{array}{c}\text { Acupuntura como } \\
\text { recurso terapêutico } \\
\text { na dor } \\
\text { e na gravidade da } \\
\text { desordem } \\
\text { temporomandibular }\end{array}$ & $\begin{array}{l}\text { Acupuntura x } \\
\text { Placebo }\end{array}$ & $\begin{array}{c}40 \\
\text { pacientes }\end{array}$ & Feminino & $\begin{array}{l}20 \text { à } 40 \\
\text { anos }\end{array}$ & $\begin{array}{c}\text { ST7 ; ST5; } \\
\text { TE17; EXHN5; } \\
\text { GB3 ; GB43; } \\
\text { LI4 e EX HN3 }\end{array}$ & $\begin{array}{l}10 \text { sessões } \\
(2 \mathrm{x} \\
\text { semana) }\end{array}$ & $\begin{array}{c}30 \\
\text { minutos }\end{array}$ & $\begin{array}{c}\text { A acupuntura } \\
\text { em conjunto } \\
\text { com a } \\
\text { fisioterapia } \\
\text { demonstrou-se } \\
\text { eficaz ao } \\
\text { tratamento. }\end{array}$ & BORIN et al., 2011 \\
\hline 6 & $\begin{array}{l}\text { Acupuntura no } \\
\text { tratamento da dor } \\
\text { lombar crônica - } \\
\text { um estudo } \\
\text { randomizado, } \\
\text { controlado por } \\
\text { placebo, com } 9 \\
\text { meses de } \\
\text { acompanhamento. }\end{array}$ & $\begin{array}{c}\text { Acupuntura x } \\
\text { Placebo x } \\
\text { Acupuntura } \\
\text { Sham }\end{array}$ & $\begin{array}{c}131 \\
\text { pacientes }\end{array}$ & $\begin{array}{l}\text { Ambos os } \\
\text { sexos }\end{array}$ & $\begin{array}{l}18 \text { à } 65 \\
\text { anos } \\
\text { (média } \\
48)\end{array}$ & $\begin{array}{c}\text { GV3, BL40, } \\
\text { GV4, BL60, } \\
\text { BL23, GB34, } \\
\text { BL25, SP6, } \\
\text { BL31, } \\
\text { Yautungdien } \\
\text { (extra meridian, } \\
\text { at the back of } \\
\text { the hand), BL } \\
32\end{array}$ & 20 sessões & $\begin{array}{c}30 \\
\text { minutos }\end{array}$ & $\begin{array}{l}\text { A acupuntura } \\
\text { demosntrou-se } \\
\text { mais eficaz do } \\
\text { que a } \\
\text { fisioterapia, } \\
\text { mas não } \\
\text { quando } \\
\text { comparado com } \\
\text { o grupo Sham. }\end{array}$ & LEIBING et al., 2002 \\
\hline 7 & $\begin{array}{c}\text { Randomised } \\
\text { controlled trial of a } \\
\text { short course of } \\
\text { traditional } \\
\text { acupuncture } \\
\text { compared with } \\
\text { usual care for } \\
\text { persistentnon- } \\
\text { specifi c low back } \\
\text { pain }\end{array}$ & $\begin{array}{l}\text { Acupuntura } x \\
\text { Cuidados } \\
\text { habituais } \\
\text { (fisioterapia) }\end{array}$ & $\begin{array}{c}241 \\
\text { pacientes }\end{array}$ & $\begin{array}{l}\text { Ambos os } \\
\text { sexos }\end{array}$ & $\begin{array}{c}18 \text { à } 65 \\
\text { anos }\end{array}$ & Não relata & $\begin{array}{l}\text { Até } 10 \\
\text { sessões }\end{array}$ & $\begin{array}{l}\text { Não } \\
\text { relata }\end{array}$ & $\begin{array}{c}\text { Houve uma } \\
\text { baixa evidência } \\
\text { sobre efeito da } \\
\text { acupuntura na } \\
\text { dor lombar } \\
\text { persistente aos } \\
12 \text { meses e uma } \\
\text { maior evidência } \\
\text { de um pequeno } \\
\text { benefício em } \\
24 \text { meses. }\end{array}$ & THOMAS et al., 2006 \\
\hline
\end{tabular}




\begin{tabular}{|c|c|c|c|c|c|c|c|c|c|c|}
\hline 8 & $\begin{array}{l}\text { Comparação da } \\
\text { eficácia do } \\
\text { tratamento com } \\
\text { acupuntura e } \\
\text { injeção de } \\
\text { anestésico local } \\
\text { para a dor lombar: } \\
\text { um ensaio clínico } \\
\text { randomizado } \\
\text { controlado. }\end{array}$ & $\begin{array}{l}\text { Acupuntura x } \\
\text { Anestésico }\end{array}$ & $\begin{array}{c}26 \\
\text { pacientes }\end{array}$ & $\begin{array}{c}14 \\
\text { homens e } \\
12 \\
\text { mulheres }\end{array}$ & $\begin{array}{c}61 \text { à } 80 \\
\text { anos }\end{array}$ & Não relata & $\begin{array}{c}4 \text { sessões } \\
(1 \mathrm{x} \\
\text { semana })\end{array}$ & $\begin{array}{l}\text { Não } \\
\text { relata }\end{array}$ & $\begin{array}{l}\text { Ambos foram } \\
\text { eficazes, porém } \\
\text { a acupuntura } \\
\text { demonstrou-se } \\
\text { mais eficaz ao } \\
\text { tratamento. }\end{array}$ & INOUE et al., 2009 \\
\hline 9 & $\begin{array}{l}\text { A acupuntura em } \\
\text { pacientes com dor } \\
\text { lombar crônica: um } \\
\text { estudo controlado } \\
\text { randomizado }\end{array}$ & $\begin{array}{c}\text { Acupuntura x } \\
\text { Placebo x } \\
\text { Acupuntura } \\
\text { Sham }\end{array}$ & $\begin{array}{c}298 \\
\text { pacientes }\end{array}$ & $\begin{array}{l}\text { Ambos os } \\
\text { sexos }\end{array}$ & $\begin{array}{c}\text { Média } 59 \\
\text { anos (+/- } \\
9) ;\end{array}$ & Não relata & 12 sessões & $\begin{array}{l}\text { Não } \\
\text { relata }\end{array}$ & $\begin{array}{l}\text { A acupuntura } \\
\text { demonstrou-se } \\
\text { eficaz com } \\
\text { relação ao } \\
\text { placebo, porém } \\
\text { não com } \\
\text { relação do } \\
\text { grupo Sham. }\end{array}$ & $\begin{array}{l}\text { BRINKHAUS et al., } \\
2006\end{array}$ \\
\hline 10 & $\begin{array}{l}\text { Acupuntura para } \\
\text { dor lombar crônica } \\
\text { em tratamento de } \\
\text { rotina: um estudo } \\
\text { observacional } \\
\text { multicêntrico }\end{array}$ & Acupuntura & $\begin{array}{c}2.564 \\
\text { pacientes }\end{array}$ & $\begin{array}{l}\text { Ambos os } \\
\text { sexos }\end{array}$ & $\begin{array}{c}\text { Média } 57 \\
\text { anos (+/- } \\
14) ;\end{array}$ & Não relata & Não relata & $\begin{array}{c}30 \\
\text { minutos }\end{array}$ & $\begin{array}{l}\text { A acupuntura } \\
\text { demonstrou-se } \\
\text { eficaz ao } \\
\text { tratamento. }\end{array}$ & $\begin{array}{l}\text { WEIDENHAMMER } \\
\text { et al., } 2007\end{array}$ \\
\hline 11 & $\begin{array}{l}\text { Qualidade de vida } \\
\text { de portadores de } \\
\text { dores crônicas em } \\
\text { tratamento com } \\
\text { acupuntura }\end{array}$ & Acupuntura & $\begin{array}{c}35 \\
\text { pacientes }\end{array}$ & $\begin{array}{l}\text { Ambos os } \\
\text { sexos }\end{array}$ & $\begin{array}{l}23 \text { à } 81 \\
\text { anos } \\
(\text { média } \\
55,2)\end{array}$ & Não relata & Não relata & $\begin{array}{l}\text { Não } \\
\text { relata }\end{array}$ & $\begin{array}{c}\text { A acupuntura } \\
\text { demonstrou-se } \\
\text { eficaz ao } \\
\text { tratamento. }\end{array}$ & BRASIL et al., 2008 \\
\hline 12 & $\begin{array}{l}\text { Efeito imediato da } \\
\text { aplicação da } \\
\text { acupuntura na dor } \\
\text { muscular tardia e } \\
\text { na capacidade de } \\
\text { contração muscular }\end{array}$ & $\begin{array}{c}\text { Acupuntura x } \\
\text { Acupuntura } \\
\text { Sham x } \\
\text { Placebo }\end{array}$ & $\begin{array}{c}30 \\
\text { pacientes }\end{array}$ & $\begin{array}{c}12 \\
\text { homens e } \\
18 \\
\text { mulheres }\end{array}$ & $\begin{array}{c}20 \text { à } 30 \\
\text { anos }\end{array}$ & $\begin{array}{l}\text { IG4, IG11, } \\
\text { E36, VB34 }\end{array}$ & 3 sessões & $\begin{array}{c}20 \\
\text { minutos }\end{array}$ & $\begin{array}{l}\text { A acupuntura } \\
\text { demonstrou-se } \\
\text { eficaz ao } \\
\text { tratamento. }\end{array}$ & PARISOTTO, 2014 \\
\hline
\end{tabular}




\begin{tabular}{|c|c|c|c|c|c|c|c|c|c|c|}
\hline 13 & $\begin{array}{l}\text { Tratamento pela } \\
\text { acupuntura das } \\
\text { lombalgias com } \\
\text { irradiação para os } \\
\text { membros inferiores } \\
\text { com lesões ósseas } \\
\text { na coluna lombar }\end{array}$ & Acupuntura & $\begin{array}{c}17 \\
\text { pacientes }\end{array}$ & $\begin{array}{l}\text { 12 } \\
\text { mulheres } \\
\mathrm{e} \quad 5 \\
\text { homens }\end{array}$ & $\begin{array}{l}37 \text { à } 75 \\
\text { anos } \\
\text { (média } \\
48,2)\end{array}$ & $\begin{array}{c}\text { M-BW-35, } \\
\text { VG-2, VG-4, } \\
\text { VB-30, B-54, } \\
\text { B-60, R-2, R-3, } \\
\text { ID-3 e M-HN- } \\
\text { 3. TA-2, TA-3, } \\
\text { VB-41, VB-43, } \\
\text { IG-2, IG-3, E- } \\
\text { 43, E-44, ID-2, } \\
\text { ID-3, B-65, B- } \\
66 .\end{array}$ & $\begin{array}{c}30 \\
\text { aplicações } \\
\text { de } \\
\text { acupuntura }\end{array}$ & $\begin{array}{c}30 \\
\text { minutos }\end{array}$ & $\begin{array}{c}\text { A acupuntura } \\
\text { demonstrou-se } \\
\text { eficaz ao } \\
\text { tratamento }\end{array}$ & $\begin{array}{l}\text { YAMAMURA et al., } \\
1995\end{array}$ \\
\hline 14 & $\begin{array}{l}\text { Acupuntura no } \\
\text { tratamento de dor } \\
\text { lombar }\end{array}$ & $\begin{array}{c}\text { Acupuntura x } \\
\text { Auriculoterapia } \\
\text { x Placebo }\end{array}$ & $\begin{array}{c}27 \\
\text { pacientes }\end{array}$ & $\begin{array}{c}6 \text { homens } \\
\mathrm{e} \\
21 \\
\text { mulheres }\end{array}$ & $\begin{array}{l}21 \text { à } 70 \\
\text { anos }\end{array}$ & $\begin{array}{c}\text { ID3, B62, B40, } \\
\text { VG4, B23, } \\
\text { B24, B25, B26, } \\
\text { B27, VB34, } \\
\text { Yintang }\end{array}$ & $\begin{array}{l}10 \text { sessões } \\
\quad(1 \mathrm{x} \\
\text { semana) }\end{array}$ & $\begin{array}{l}\text { Não } \\
\text { relata }\end{array}$ & $\begin{array}{c}\text { A acupuntura e } \\
\text { a } \\
\text { auriculoterapia } \\
\text { demonstraram- } \\
\text { se eficaz ao } \\
\text { tratamento, } \\
\text { porém a } \\
\text { acupuntura } \\
\text { sistêmica foi } \\
\text { mais eficaz. }\end{array}$ & $\begin{array}{l}\text { CARVALHO et al, } \\
2015\end{array}$ \\
\hline 15 & $\begin{array}{l}\text { Tratamento } \\
\text { fisioterapêutico por } \\
\text { meio da acupuntura } \\
\text { nas lombalgias }\end{array}$ & Acupuntura & $\begin{array}{c}8 \\
\text { individuos }\end{array}$ & Feminino & $\begin{array}{l}35 \text { à } 45 \\
\text { anos }\end{array}$ & Não relata & 5 sessões & $\begin{array}{c}40 \\
\text { minutos }\end{array}$ & $\begin{array}{c}\text { A acupuntura } \\
\text { demonstrou-se } \\
\text { eficaz ao } \\
\text { tratamento. }\end{array}$ & SILVA et al, 2005 \\
\hline
\end{tabular}

Fonte: O autor (2016). 
TABELA 2. Acupuntura na Fibromialgia.

\begin{tabular}{|c|c|c|c|c|c|c|c|c|c|c|}
\hline ITEM & TÍTULO & $\begin{array}{c}\text { COMPARAÇÃ } \\
\text { O }\end{array}$ & $\begin{array}{l}\text { PACIEN } \\
\text { TES }\end{array}$ & SEXO & IDADE & PONTOS & SESSÕES & TEMPO & CONCLUSÃO & $\begin{array}{c}\text { REFERÊNCI } \\
\text { A }\end{array}$ \\
\hline 1 & $\begin{array}{l}\text { Acupuntura na } \\
\text { fibromialgia: um } \\
\text { estudo } \\
\text { randomizado- } \\
\text { controlado } \\
\text { abordando a } \\
\text { resposta imediata } \\
\text { da dor }\end{array}$ & $\begin{array}{c}\text { Acupuntura } \mathrm{x} \\
\text { Placebo }\end{array}$ & $\begin{array}{c}36 \\
\text { pacientes }\end{array}$ & $\begin{array}{l}\text { Feminin } \\
\quad \mathrm{o}\end{array}$ & $\begin{array}{c}\text { Idade } \\
\text { média de } \\
49,2 \pm \\
11,8 \mathrm{e} \\
52,0 \pm \\
7,57\end{array}$ & $\begin{array}{l}\text { PC6, C7, BP6, } \\
\text { IG4, F2 e E36 } \\
\text { bilateralmente }\end{array}$ & 1 sessão & $\begin{array}{c}20 \\
\text { minutos }\end{array}$ & $\begin{array}{c}\text { A acupuntura } \\
\text { demonstrou-se } \\
\text { eficaz ao } \\
\text { tratamento. }\end{array}$ & $\begin{array}{l}\text { STIVAL et } \\
\text { al., } 2014\end{array}$ \\
\hline 2 & $\begin{array}{c}\text { Acupuntura: } \\
\text { Melhorando a } \\
\text { qualidade de vida } \\
\text { das mulheres com } \\
\text { fibromialgia }\end{array}$ & Acupuntura & $\begin{array}{c}8 \\
\text { pacientes }\end{array}$ & $\begin{array}{c}\text { Feminin } \\
\quad \mathrm{o}\end{array}$ & $\begin{array}{l}\text { Não } \\
\text { relata }\end{array}$ & Não relata & 15 sessões & não relata & $\begin{array}{l}\text { A acupuntura } \\
\text { demonstrou-se } \\
\text { eficaz ao } \\
\text { tratamento }\end{array}$ & $\begin{array}{l}\text { OLIVEIRA et } \\
\text { al., } 2008\end{array}$ \\
\hline 3 & $\begin{array}{c}\text { Efeito da } \\
\text { acupuntura na } \\
\text { melhora da dor, } \\
\text { sono e qualidade } \\
\text { de vida em } \\
\text { pacientes } \\
\text { fibromiálgicos: } \\
\text { estudo preliminar }\end{array}$ & $\begin{array}{l}\text { Acupuntura } \mathrm{X} \\
\text { Acupuntura nos } \\
\text { tender points }\end{array}$ & $\begin{array}{c}12 \\
\text { pacientes }\end{array}$ & $\begin{array}{l}\text { Feminin } \\
\quad \mathrm{o}\end{array}$ & $\begin{array}{c}\text { Idade } \\
\text { média de } \\
45,6 \pm \\
7,06 \\
\text { e 44,28 } \\
7,22\end{array}$ & Não relata & 8 sessões & $\begin{array}{c}25 \\
\text { minutos }\end{array}$ & $\begin{array}{l}\text { A acupuntura nos } \\
\text { tender points foi } \\
\text { mais eficaz. }\end{array}$ & $\begin{array}{c}\text { TAKIGUCHI } \\
\text { et al., } 2008\end{array}$ \\
\hline 4 & $\begin{array}{c}\text { Acupuntura na } \\
\text { fibromialgia: } \\
\text { Um estudo de } \\
\text { caso }\end{array}$ & Acupuntura & 1 paciente & $\begin{array}{c}\text { Feminin } \\
\mathrm{o}\end{array}$ & $\begin{array}{l}\text { Não } \\
\text { relata }\end{array}$ & $\begin{array}{c}\text { C3, VG - 20, } \\
\text { VC 4, VB 34, } \\
\text { R6+P7), e } \\
\text { aurículoacupunt } \\
\text { ura }\end{array}$ & 9 sessões & $\begin{array}{c}40 \\
\text { minutos }\end{array}$ & $\begin{array}{c}\text { A acupuntura } \\
\text { demonstrou-se } \\
\text { eficaz ao } \\
\text { tratamento }\end{array}$ & $\begin{array}{l}\text { LEMOS et } \\
\text { al., } 2006\end{array}$ \\
\hline
\end{tabular}




\begin{tabular}{|c|c|c|c|c|c|c|c|c|c|c|}
\hline 5 & $\begin{array}{c}\text { Eficácia da } \\
\text { acupuntura sobre } \\
\text { a dor e a } \\
\text { qualidade de vida } \\
\text { em mulheres com } \\
\text { fibromialgia }\end{array}$ & Acupuntura & $\begin{array}{c}4 \\
\text { pacientes }\end{array}$ & $\begin{array}{c}\text { Feminin } \\
\mathrm{o}\end{array}$ & $\begin{array}{c}30 \text { à } 50 \\
\text { anos }\end{array}$ & Não relata & $\begin{array}{l}\text { três } \\
\text { meses, } \\
\text { duas } \\
\text { vezes por } \\
\text { semana }\end{array}$ & $\begin{array}{c}20 \\
\text { minutos }\end{array}$ & $\begin{array}{c}\text { A acupuntura } \\
\text { demonstrou-se } \\
\text { eficaz ao } \\
\text { tratamento }\end{array}$ & $\begin{array}{l}\text { MENDONÇ } \\
\text { A, } 2006\end{array}$ \\
\hline 6 & $\begin{array}{l}\text { Acupuntura para } \\
\text { a fibromialgia na } \\
\text { atenção básica: } \\
\text { um estudo } \\
\text { controlado } \\
\text { randomizado }\end{array}$ & $\begin{array}{c}\text { Acupuntura } \mathrm{x} \\
\text { Acupuntura } \\
\text { Sham }\end{array}$ & $\begin{array}{c}153 \\
\text { pacientes }\end{array}$ & $\begin{array}{l}\text { Não } \\
\text { relata }\end{array}$ & $\begin{array}{l}\text { Maiores } \\
\text { de } 17 \\
\text { anos }\end{array}$ & Não relata & $\begin{array}{c}9 \text { sessões } \\
(1 \mathrm{x} \\
\text { semana })\end{array}$ & $\begin{array}{c}20 \\
\text { minutos }\end{array}$ & $\begin{array}{c}\text { A acupuntura } \\
\text { demonstrou-se } \\
\text { eficaz ao } \\
\text { tratamento em } \\
\text { comparação com o } \\
\text { grupo Sham. }\end{array}$ & $\begin{array}{c}\text { VAS et al., } \\
2016\end{array}$ \\
\hline 7 & $\begin{array}{c}\text { Efeitos da } \\
\text { acupuntura para } \\
\text { tratar a } \\
\text { fibromialgia: Um } \\
\text { estudo controlado } \\
\text { randomizado } \\
\text { preliminar }\end{array}$ & Acupuntura & $\begin{array}{c}16 \\
\text { pacientes }\end{array}$ & $\begin{array}{c}13 \\
\text { mulhere } \\
\text { s e } \\
3 \\
\text { homens }\end{array}$ & $\begin{array}{c}25 \text { à } 63 \\
\text { anos }\end{array}$ & Não relata & $\begin{array}{c}5 \text { e } 10 \\
\text { sessões }\end{array}$ & $\begin{array}{c}15 \\
\text { minutos }\end{array}$ & $\begin{array}{l}\text { A acupuntura } \\
\text { demonstrou-se } \\
\text { eficaz ao } \\
\text { tratamento }\end{array}$ & $\begin{array}{c}\text { ITOH E } \\
\text { KITAKOJ, } \\
2010\end{array}$ \\
\hline 8 & $\begin{array}{c}\text { Um ensaio } \\
\text { clínico } \\
\text { randomizado do } \\
\text { tratamento da } \\
\text { fibromialgia com } \\
\text { acupuntura em } \\
\text { comparação com } \\
\text { fluoxetina }\end{array}$ & $\begin{array}{c}\text { Acupuntura } \mathrm{x} \\
\text { Placebo } \\
\text { (Fluoxetina) }\end{array}$ & $\begin{array}{c}30 \\
\text { pacientes }\end{array}$ & $\begin{array}{c}\text { Feminin } \\
\mathrm{o}\end{array}$ & $\begin{array}{c}25 \text { à } 65 \\
\text { anos }\end{array}$ & $\begin{array}{c}\text { ST-36, P-34, } \\
\text { RN-6, SP-6, IL- } \\
\text { 4, St-44, BL-40, } \\
\text { HT-7 e DU-20 }\end{array}$ & 6 sessões & $\begin{array}{c}30 \\
\text { minutos }\end{array}$ & $\begin{array}{l}\text { A acupupuntura } \\
\text { mostrou-se mais } \\
\text { eficaz em } \\
\text { comparação com a } \\
\text { utilização da } \\
\text { Fluoxetina na } \\
\text { redução da dor. }\end{array}$ & $\begin{array}{c}\text { HADIANFA } \\
\text { RD e } \\
\text { PARIZI, } 2012\end{array}$ \\
\hline 9 & $\begin{array}{l}\text { Tratamento da } \\
\text { fibromialgia com } \\
\text { acupuntura } \\
\text { fórmula: } \\
\text { investigação de } \\
\text { colocação da } \\
\text { agulha, a } \\
\text { estimulação da }\end{array}$ & $\begin{array}{c}\text { Acupuntura } \mathrm{x} \\
\text { Acupuntura } \\
\text { Sham }\end{array}$ & $\begin{array}{c}114 \\
\text { pacientes }\end{array}$ & \begin{tabular}{l}
\multicolumn{1}{c}{106} \\
mulhere \\
s e 8 \\
homens
\end{tabular} & $\begin{array}{l}\text { Não } \\
\text { relata }\end{array}$ & $\begin{array}{c}\text { Du 20, LI 11, LI } \\
\text { 4, GB 34, } \\
\text { bilateral } \\
\text { ST36, Sp6, Liv } \\
\text { 3 e Ear- } \\
\text { Shenmen }\end{array}$ & 18 sessões & $\begin{array}{c}20 \\
\text { minutos }\end{array}$ & $\begin{array}{c}\text { A acupuntura } \\
\text { demonstrou-se } \\
\text { eficaz ao } \\
\text { tratamento }\end{array}$ & $\begin{array}{c}\text { HARRIS et } \\
\text { al., } 2005\end{array}$ \\
\hline
\end{tabular}


agulha, e

frequência de

tratamento.

\begin{tabular}{|c|c|c|c|c|c|c|c|c|c|c|}
\hline 10 & $\begin{array}{c}\text { Um ensaio } \\
\text { clínico } \\
\text { randomizado de } \\
\text { acupuntura em } \\
\text { comparação com } \\
\text { a acupuntura } \\
\text { sham na } \\
\text { fibromialgia. }\end{array}$ & $\begin{array}{l}\text { Acupuntura } \mathrm{x} \\
\text { Acupuntura } \\
\text { Sham }\end{array}$ & $\begin{array}{c}96 \\
\text { pacientes }\end{array}$ & $\begin{array}{l}\text { Não } \\
\text { relata }\end{array}$ & $\begin{array}{l}\text { Não } \\
\text { relata }\end{array}$ & Não relata & $\begin{array}{l}24 \text { sessões } \\
(2 \mathrm{x} \\
\text { semana })\end{array}$ & $\begin{array}{c}30 \\
\text { minutos }\end{array}$ & $\begin{array}{c}\text { A acupuntura não } \\
\text { foi mais eficaz do } \\
\text { que a acupuntura } \\
\text { sham no alívio da } \\
\text { dor. }\end{array}$ & $\begin{array}{l}\text { ASSEFI et } \\
\text { al., } 2005\end{array}$ \\
\hline 11 & $\begin{array}{l}\text { O tratamento da } \\
\text { dor da } \\
\text { fibromialgia pela } \\
\text { acupuntura }\end{array}$ & Acupuntura & $\begin{array}{c}29 \\
\text { pacientes }\end{array}$ & $\begin{array}{c}25 \\
\text { mulhere } \\
\text { s e } \\
4 \\
\text { homens }\end{array}$ & $\begin{array}{l}\text { idade } \\
\text { média de } \\
48,2+/- \\
2,0 \text { anos }\end{array}$ & Não relata & $\begin{array}{l}6 \text { sessões } \\
(1 \mathrm{x} \\
\text { semana })\end{array}$ & não relata & $\begin{array}{l}\text { A acupuntura } \\
\text { demonstrou-se } \\
\text { eficaz ao } \\
\text { tratamento }\end{array}$ & $\begin{array}{l}\text { SPROTT et } \\
\text { al., } 1998\end{array}$ \\
\hline 12 & $\begin{array}{c}\text { Acupuntura } \\
\text { Tradicional } \\
\text { Chinesa e } \\
\text { Acupuntura } \\
\text { Placebo (Sham) } \\
\text { são diferenciados } \\
\text { por seus efeitos } \\
\text { sobre } \mu \text {-opióides } \\
\text { receptores } \\
\text { (MORs) }\end{array}$ & $\begin{array}{l}\text { Acupuntura } x \\
\text { Acupuntura } \\
\text { Sham }\end{array}$ & $\begin{array}{c}20 \\
\text { pacientes }\end{array}$ & $\begin{array}{l}\text { Feminin } \\
\qquad\end{array}$ & $\begin{array}{l}18 \text { à } 75 \\
\text { anos } \\
\text { (média de } \\
44,3 \\
\text { anos) }\end{array}$ & $\begin{array}{l}\text { Du20, ouvido } \\
\text { Shenmen, LI4, } \\
\text { LI11, SP6 Liv3, } \\
\text { GB34 e ST36 } \\
\text { bilateral }\end{array}$ & 9 sessões & não relata & $\begin{array}{l}\text { A acupuntura } \\
\text { demonstrou-se } \\
\text { eficaz ao } \\
\text { tratamento }\end{array}$ & $\begin{array}{l}\text { HARRIS et } \\
\text { al., } 2009\end{array}$ \\
\hline 13 & $\begin{array}{l}\text { Eficácia da } \\
\text { acupuntura no } \\
\text { alívio da dor } \\
\text { refratária ao } \\
\text { tratamento } \\
\text { medicamentoso } \\
\text { convencional. }\end{array}$ & Acupuntura & $\begin{array}{c}225 \\
\text { pacientes }\end{array}$ & $\begin{array}{l}\text { Não } \\
\text { relata }\end{array}$ & $\begin{array}{c}19 \text { à } 92 \\
\text { anos } \\
\text { (média de } \\
53 \text { anos) }\end{array}$ & Não relata & $\begin{array}{l}\text { Habitualm } \\
\text { ente } 10 \\
\text { sessões } \\
(1 \mathrm{x} \\
\text { semana) }\end{array}$ & $\begin{array}{c}20 \\
\text { minutos }\end{array}$ & $\begin{array}{l}\text { A acupuntura } \\
\text { demonstrou-se } \\
\text { eficaz ao } \\
\text { tratamento. }\end{array}$ & CHAO, 2009 \\
\hline
\end{tabular}




\begin{tabular}{|c|c|c|c|c|c|c|c|c|c|c|}
\hline 14 & $\begin{array}{c}\text { Efeito da } \\
\text { acupuntura na dor } \\
\text { em pacientes com } \\
\text { fibromialgia }\end{array}$ & Acupuntura & $\begin{array}{c}9 \\
\text { pacientes }\end{array}$ & $\begin{array}{l}\text { Não } \\
\text { relata }\end{array}$ & $\begin{array}{l}\text { Não } \\
\text { relata }\end{array}$ & Não relata & $\begin{array}{l}\text { Média } \\
7,75 \\
\text { sessões }\end{array}$ & $\begin{array}{l}\text { Não } \\
\text { relata }\end{array}$ & $\begin{array}{l}\text { A acupuntura } \\
\text { demonstrou-se } \\
\text { eficaz ao } \\
\text { tratamento }\end{array}$ & $\begin{array}{c}\text { PEREIRA E } \\
\text { GONÇALVE } \\
\text { S }\end{array}$ \\
\hline 15 & $\begin{array}{l}\text { Acupuntura em } \\
\text { adolescentes com } \\
\text { fibromialgia } \\
\text { juvenil }\end{array}$ & Acupuntura & $\begin{array}{c}13 \\
\text { pacientes }\end{array}$ & $\begin{array}{c}12 \\
\text { mulhere } \\
\text { s e } \\
1 \\
\text { homem }\end{array}$ & $\begin{array}{c}10 \text { à } 18 \\
\text { anos }\end{array}$ & $\begin{array}{c}\text { ExCP3, IG11, } \\
\text { TA6, IG4, } \\
\text { RM12; E36, } \\
\text { VB34, F3, B11, } \\
\text { B15, B18, B20, } \\
\text { B23. }\end{array}$ & 11 sessões & $\begin{array}{l}\text { Não } \\
\text { relata }\end{array}$ & $\begin{array}{c}\text { A acupuntura } \\
\text { demonstrou-se } \\
\text { eficaz ao } \\
\text { tratamento }\end{array}$ & $\begin{array}{l}\text { DIAS et al., } \\
2012\end{array}$ \\
\hline 16 & $\begin{array}{l}\text { Efeitos da } \\
\text { acupuntura, } \\
\text { eletroacupuntura } \\
\text { e moxabustão na } \\
\text { qualidade de vida } \\
\text { e no controle da } \\
\text { dor em mulheres } \\
\text { fibromiálgicas }\end{array}$ & $\begin{array}{l}\text { Acupuntura x } \\
\text { Eletroacupuntur } \\
\text { a x Moxa }\end{array}$ & $\begin{array}{c}30 \\
\text { pacientes }\end{array}$ & $\begin{array}{l}\text { Feminin } \\
\quad \mathrm{o}\end{array}$ & $\begin{array}{l}20 \text { à } 60 \\
\text { anos } \\
\text { (média de } \\
46,90 \pm \\
9,24)\end{array}$ & $\begin{array}{c}\text { PC6, IG4, } \\
\text { VB34, BP6 e F3 }\end{array}$ & $\begin{array}{l}8 \text { sessões } \\
(1 \mathrm{x} \\
\text { semana })\end{array}$ & $\begin{array}{c}30 \\
\text { minutos }\end{array}$ & $\begin{array}{l}\text { Nenhum dos três } \\
\text { tratamentos } \\
\text { mostrou-se eficaz } \\
\text { na redução da dor } \\
\text { das pacientes com } \\
\text { fibromialgia. }\end{array}$ & DIAS, 2012 \\
\hline 17 & $\begin{array}{c}\text { Efeitos da } \\
\text { acupuntura em } \\
\text { pacientes com } \\
\text { fibromialgia: } \\
\text { protocolo de um } \\
\text { estudo } \\
\text { randomizado } \\
\text { controlado }\end{array}$ & $\begin{array}{c}\text { Acupuntura } \mathrm{x} \\
\text { Acupuntura } \\
\text { Sham }\end{array}$ & $\begin{array}{c}156 \\
\text { pacientes }\end{array}$ & $\begin{array}{l}\text { Não } \\
\text { relata }\end{array}$ & 17 anos & Não relata & $\begin{array}{c}9 \text { sessões } \\
(1 \mathrm{x} \\
\text { semana })\end{array}$ & $\begin{array}{c}20 \\
\text { minutos }\end{array}$ & $\begin{array}{l}\text { O estudo não foi } \\
\text { concluído pois os } \\
\text { resultados seriam } \\
\text { analisados } \\
\text { futuramente. }\end{array}$ & $\begin{array}{l}\text { VAS et al., } \\
2016\end{array}$ \\
\hline 18 & $\begin{array}{l}\text { Melhoria nos } \\
\text { sintomas da } \\
\text { fibromialgia com } \\
\text { acupuntura: } \\
\text { resultados de um } \\
\text { estudo } \\
\text { randomizado } \\
\text { controlado. }\end{array}$ & $\begin{array}{l}\text { Acupuntura } \mathrm{x} \\
\text { Placebo }\end{array}$ & $\begin{array}{c}50 \\
\text { pacientes }\end{array}$ & $\begin{array}{l}\text { Não } \\
\text { relata }\end{array}$ & $\begin{array}{c}\text { Idade } \\
\text { média de } \\
51,7 \pm \\
14,1 \mathrm{e} \\
47,9 \pm \\
11,2 \text { anos }\end{array}$ & $\begin{array}{l}\text { IG4, E36, F2, } \\
\text { BP6, PC6 e } \\
\text { C7 bilaterais. }\end{array}$ & 6 sessões & $\begin{array}{c}20 \\
\text { minutos }\end{array}$ & $\begin{array}{c}\text { A acupuntura } \\
\text { demonstrou-se } \\
\text { eficaz ao } \\
\text { tratamento }\end{array}$ & $\begin{array}{l}\text { MARTIN et } \\
\text { al., } 2006\end{array}$ \\
\hline
\end{tabular}




\begin{tabular}{|c|c|c|c|c|c|c|c|c|c|c|}
\hline 19 & $\begin{array}{l}\text { Um estudo } \\
\text { controlado } \\
\text { randomizado de } \\
\text { acupuntura } \\
\text { adicionada ao } \\
\text { tratamento usual } \\
\text { para fibromialgia }\end{array}$ & $\begin{array}{l}\text { Acupuntura } \mathrm{x} \\
\text { Antidepressivo } \\
\text { + exercício }\end{array}$ & $\begin{array}{c}58 \\
\text { pacientes }\end{array}$ & $\begin{array}{l}\text { Não } \\
\text { relata }\end{array}$ & $\begin{array}{c}20 \text { à } 70 \\
\text { anos }\end{array}$ & Tender Points & $\begin{array}{c}20 \text { sessões } \\
(2 \mathrm{x} \\
\text { semana })\end{array}$ & não relata & $\begin{array}{c}\text { A acupuntura } \\
\text { demonstrou-se } \\
\text { eficaz ao } \\
\text { tratamento. }\end{array}$ & $\begin{array}{c}\text { TARGINO et } \\
\text { al., } 2010\end{array}$ \\
\hline 20 & $\begin{array}{l}\text { Tratamento da } \\
\text { dor na } \\
\text { fibromialgia com } \\
\text { acupuntura }\end{array}$ & $\begin{array}{c}\text { Acupuntura }+ \\
\text { Tratamento } \\
\text { Convencional x } \\
\text { Controle }\end{array}$ & $\begin{array}{c}58 \\
\text { pacientes }\end{array}$ & $\begin{array}{l}\text { Não } \\
\text { relata }\end{array}$ & $\begin{array}{c}27 \text { à } 70 \\
\text { anos }\end{array}$ & $\begin{array}{c}\text { Ig4, Id3, PC6, } \\
\text { UB34, BP6 }\end{array}$ & $\begin{array}{c}20 \text { sessões } \\
(2 \mathrm{x} \\
\text { semana })\end{array}$ & $\begin{array}{c}20 \\
\text { minutos }\end{array}$ & $\begin{array}{c}\text { A acupuntura } \\
\text { demonstrou-se } \\
\text { eficaz ao } \\
\text { tratamento. }\end{array}$ & $\begin{array}{l}\text { ARAUJO, } \\
2007\end{array}$ \\
\hline
\end{tabular}

Fonte: $\mathrm{O}$ autor (2016). 


\section{Conclusão}

Com base nos dados obtidos nos diversos estudos sobre o tema, observou-se que não há uma padronização na técnica de acupuntura, pois algumas variáveis como: tipo de dor, idade, sexo, pontos utilizados, quantidade de pacientes, quantidade e tempo das sessões e métodos de comparação variaram muito e em algumas situações eles não foram se querem mencionados nos trabalhos. Sendo assim, não existe um protocolo de tratamento adequado na acupuntura que esclareça o número de sessões necessárias para obter-se efeito terapêutico para alívio da dor. Além disso, a literatura é escassa, os resultados controversos e os trabalhos publicados possuem pouco rigor científico complicaram ainda mais a conclusão deste trabalho.

O uso da acupuntura foi eficaz na redução da dor na maioria dos artigos abordados. Alguns autores utilizaram outros métodos de tratamento como alongamento, fisioterapia, anestésicos e antidepressivos e demonstraram serem menos eficazes na redução da dor em comparação com a acupuntura.

Diante dos resultados apresentados e levando-se em conta que os materiais utilizados na acupuntura são simples, seguros, econômicos, de fácil manipulação e que praticamente não causam efeitos colaterais, demonstra que essa técnica apresenta maiores vantagens com relação às demais.

A acupuntura também se mostrou eficaz na melhora da qualidade de vida, surgindo efeitos benéficos na capacidade funcional do nosso organismo, nos aspectos social e emocional e na saúde mental.

\section{Referências}

1. Yamamura Y. Acupuntura tradicional: A arte de inserir. São Paulo: Ed. Roca; 1993.

2. Wen TS. Acupuntura Clássica Chinesa. São Paulo: Ed. Cultrix; 1985.

3. Min LS, Darella ML, Pereira OA. Curso básico - acupuntura e medicina tradicional chinesa. Ed. Ipe/MTC; 2000.

4. Maciocia G. Os fundamentos da medicina chinesa. São Paulo: Ed. Roca; 1996. 
5. Lee PK, Anderson TW, Modell JH, Saga SA. Treatment of chronic pain with acupuncture. Jama. 1975;232(11):1133-35.

6. Mann F. Acupuntura - A antiga arte Chinesa de curar. São Paulo: Hemus; 1971.

7. Maciocia G. Diagnóstico na Medicina Chinesa - Um Guia Geral. São Paulo: Roca; 2006.

8. Campiglia H. Psique e Medicina Tradicional Chinesa. São Paulo: Roca; 2004.

9. Wu DZ. Acupuncture and neurophisiology. Clinical Neurology and Neurosurgery. 1990;92(1):13-25.

10. Alvarenga TF, Amaral CG, Steffen CP. Ação da acupuntura na neurofisiologia da dor: revisão bibliográfica. Revista Amazônia Science \& Health. 2014;2(4):29-36.

11. Zotelli VLR, Rando-Meirelles MP, Sousa MLR. Uso da acupuntura no manejo da dor em pacientes com alterações na articulação temporomandibular (ATM). Revista de Odontologia da Universidade de São Paulo. 2010;22(2):185-88.

12. Hwang YC. Anatomy and classification of acupoints. Problems in Veterinary Medicine. 1992;4(1):12-15.

13. Salazar J, Reyes R. Analgesia por acupuntura. Rev Cubana Méd Milit. 2004;33(1):1-6.

14. Erthal V, Nohama P, Santos ARS. Estudo Experimental da Ação Antinociceptiva da Acupuntura e da Radiação Laser no Acuponto E36 (ZUSANLI). In: 21. Congresso Brasileiro de Engenharia Biomédica, 2008: Salvador, Bahia; 2008. p. 1-4.

15. Palmeira GA. Acupuntura no ocidente. Cadernos de Saúde Pública. 1990;6(1):117-28.

16. Guyton AC, Hall JE. Tratado de fisiologia médica. Rio de Janeiro: Ed. Elsevier; 2011.

17. Birch S, Jamison RN. Controlled trial of Japanese acupuncture for chronic myofascial neck pain: assessment of specific and nonspecific effects of treatment. Clinical Journal of Pain. 1998;14(3):248-55.

18. Branco CA, Fonseca RB, Oliveira TRC, Gomes VL, Fernandes Neto AJ. Acupuntura como tratamento complementar nas disfunções temporomandibulares: revisão da literatura. Revista de Odontologia da UNESP, São Paulo. 2005;34(1):11-16.

19. Smith BH, Elliott AM, Chambers WA, Cairns Smith, W.; Hannaford, P. C.; Penny, K. The impact of chronic pain in the community. Fam Pract. 2001;18(3):292-99.

20. Wink S, Cartana MHF. Promovendo o autocuidado em pacientes com cefaléia por meio da perspectiva oriental de saúde. Revista Brasileira de Enfermagem. 2007;60(2):225-28.

21. Yamamura Y. Acupuntura: a arte de inserir. São Paulo: Roca; 2001.

22. Saidah R, Chueire AG, Rejaili WA, Peres NRB, Silva JBG, Schiavo F. Acupuntura em relação à dor, atividade física e a necessidade de apoio para a marcha no pós-operatório das cirurgias artroscópicas no joelho. Acta Ortop. Bras. 2003;11(1):5-10.

23. Sola AE, Bonica JJ. Myofascial pain syndromes. In The Management of pain. Philadelphia: Lea \& Febiger; 1990.

24. Loh L, Nathan PW, Schott GD, Zilkha KJ. Acupuncture versus medical treatment for migraine and muscle tension headaches. $\mathbf{J}$ Neurol Neurosurg Psychiatry. 1984;47(4):33337.

25. Cherkin DC, Eisenberg D, Sherman KJ, Barlow W, Kaptchuk TJ, Street J, Deyo RA. Randomized trial comparing traditional chinese medical acupuncture, therapeutic massage, and self-care education for chronic low back Pain. Archives of Internal Medicine. 2001;161(8):1081-88.

26. Merskey H, Bogduk N. Classification of chronic pain. Seattle: IASP Press; 1994. 
27. Marcus DA. Fibromyalgia: Diagnosis and Treatment Options. Gender Medicine. 2009;6(2):139-51.

28. Heymann RE, Paiva ES, Helfenstein Junior M, Pollak DF, Martinez JE, Provenza JR et al. Consenso brasileiro do tratamento da Fibromialgia. Revista Brasileira de Reumatologia. 2010;50(1):56-66.

29. Pillemer SR, Bradley LA, Crofford LJ, Moldofsky H. Chrousos GP. The neuroscience and endocrinology of fibromyalgia. Arthritis \& Rheumatology. 1997;40:1928-39.

30. Dadabhoy D, Crofford LL, Spaeth M, Russell IJ, Clauw DJ. Biology and therapy of fibromyalgia. Evidence-based biomarkers for fibromyalgia syndrome. Arthritis Research \& Therapy; 2008;10(4):1-18.

31. Scotton AS, Souza VA, Fraga RO, Vassalo S, Lisboa RV, Lisboa TV. Fibromialgia. Revista Brasileira de Medicina. 2010;67(7):221-27.

32. Marques AP, Assumpção A, Matsutani LA. Fibromialgia e Fisioterapia: Avaliação e Tratamento. São Paulo: Manole; 2015.

33. Senna ER, Barros ALP, Silva EO, Costa IF, Pereira LVB, Ciconelli RN et al. Prevalence of rheumatic diseases in Brazil: a study using the COPOCORD approach. J Rheumatol. 2004;31(3):594-97.

34. Cagnie B, Coppieters I, Denecker S, Six J, Danneels L, Meeus M. Central sensitization in fibromyalgia? A systematic review on structural and functional brain MRI. Semin Arthritis Rheum. 2014;44(1):68-75.

35. Maestu C, Vazquez JM, Del Rio D, Gomez-Arguelles JM, Del Pozo F, Nevado A. Increased brain responses during subjectivelymatched

mechanical pain stimulation in fibromyalgia patients as evidenced by MEG. Clin. Neurophysiol. 2013;124(4):752-60.

36. Sanita PCVM, Moraes TSM, Santos FM. Analysis of the effect of acupuncture in the treatment of fibromyalgia: literature review.
Manual Therapy, Posturology \& Rehabilitation Journal. 2014;12:67-72.

37. Barbosa AM, Neto GAM, Vale LA, Pirett VM. Acupuntura no tratamento da fibromialgia: uma revisão de literatura. Revista Movimenta. 2013;6(2).

38. Maciocia G. Os Fundamentos da Medicina Chinesa. São Paulo: Roca; 2004.

39. Sprott H, Franke S, Kluge H, Heig G. Pain Treatment of Fibromyalgia by Acupuncture. Rheumatol Int. 1998;18(1):3536.

40. Bannerman RH. The World Health Organization viewpoint on acupuncture. American Journal of Acupuncture. 1980;8(3):231-35.

41. Itoh K, Kitakoji H. Effects of acupuncture to treat fibromyalgia: A preliminary randomised controlled trial. Chinese Medicine. 2010;5(11).

42. Barcelos CC, Zumstein A, Braga AFA. Acupuntura e alongamento no tratamento da dor lombar crônica. Estudo comparativo. Revista Brasileira de Fisioterapia. 2007;11 Suppl 1:41-41.

43. Borin GS, Corrêa EC, Silva AMT, Milanesi JM. Acupuntura como recurso terapêutico na dor e na gravidade da desordem temporomandibular. Revista Fisioterapia e Pesquisa. 2011;18(3):217-22.

44. Leibing E, Leonhardtb U, Kosterc G, Goerlitzd A, Rosenfeldtc JA, Hilgersd R, et al. Acupuncture treatment of chronic low-back pain - a randomized, blinded, placebocontrolled trial with 9-month follow-up. Pain. 2002;96(1-2):189-96.

45. Thomas KJ, Macpherson H, Thorpe L, Brazier J, Fitter M, Campbell MJ, et al. Randomised controlled trial of a short course of traditional acupuncture compared with usual care for persistent non-specific low back pain. BMJ. 2006;333(7569):626.

46. Inoue M, Hojo T, Nakajima M, Kitakoji $\mathrm{H}$, Itoi M. Comparison of the effectiveness of acupuncture treatment and local anaesthetic 
injection for low back pain: a randomised controlled clinical Trial. Acupunct Med. 2009;27(4):174-77.

47. Brinkhaus B, Witt CM, Jena S, Linde K, Streng A, Wagenpfeil S, Irnich D, et al. Acupuncture in patients with chronic low back pain: a randomized controlled Trial. Archives of Internal Medicine. 2006;166(4):450-57.

48. Parisotto D. Efeito imediato da aplicação da acupuntura na dor muscular tardia e na capacidade de contração muscular (dissertação). Curitiba: Universidade Federal do Paraná; 2014.

49. Carvalho PC, Oba MV, Silva LCM, Scandiuzzi RJ, Soares DW, Ornela RG. Acupuntura no tratamento de dor lombar. Journal of Acupuncture and Meridian Studies.2015;33(4):333-38.

50. Barbosa MFGC. Acupuntura na síndrome do túnel do carpo: Relato de um caso. Revista Brasileira de Fisioterapia. 2007;11n.Suppl:43-43.

51. Sousa MLR, Mashuda CS, Sato JE, Siqueira JTT. Effects of acupuncture in adults with temporomandibular disorders. Revista Dor. 2014;15(2):87-90.

52. Furlaneto SG, Alcarde KJP. Acupuntura no Tratamento de Bursite no Ombro (monografia). Bauru: Centro de Estudos de Terapias Naturais; 2016.

53. Weidenhammer W, Linde K, Streng A. Acupuncture for chronic low back pain in routine care: a multicenter observational study. The Clinical Journal of Pain, Hagerstown. 2007;23(2):128-35.

54. Brasil VV, Zatta LT, Cordeiro JABL, Silva AMTC, Zatta DT, Barbosa MA. Qualidade de vida de portadores de dores crônicas em tratamento com acupuntura. Revista Eletrônica de Enfermagem.2008;10(2):383-94.

55. Yamamura Y, Filho JL, Neto NF, Puertas EB, Tabosa A. Tratamento pela acupuntura das lombalgias com irradiação para os membros inferiores com lesões ósseas na coluna lombar. Acta Ortopédica Brasileira. $1995 ; 3(2)$.

56. Silva AFG, Bandeira LPF, Rossafa P, Beraldo PC. Tratamento fisioterapêutico por meio da acupuntura nas lombalgias. Rev. Rubs. 2005;1(2):1-50.

57. Stival RSM, Cavalheiro PR, Stasiak CES, Galdino DT, Hoekstra BE, Schafranski MD. Acupuncture in fibromyalgia: a randomized, controlled study addressing the immediate pain response. Rev. Brasileira Reumatologia. 2014;54(6):431-36.

58. Takiguchi RS, Fukuhara VS, Sauer JF, Assumpção A, Marques AP. Efeito da acupuntura na melhora da dor, sono e qualidade de vida em pacientes fibromiálgicos: estudo preliminar. Fisioterapia e Pesquisa. 2008;15(3):280-84.

59. Vas J, Modesto M, Aguilar I, SantosRey K, Benítez-Parejo N, Rivas-Ruiz F. Effects of acupuncture on patients with fibromyalgia: study protocol of a multicentre randomized controlled trial. Trials. 2011;12(59).

60. Hadianfard MJ, Parizi MH. A randomized clinical trial of fibromyalgia treatment with acupuncture compared with fluoxetine. Iran Red Crescent Med J. 2012;14(10):631-40.

61. Harris RE, Tian X, Williams DA, Tian TX, Cupps TR, Petzke F, et al. Treatment of fibromyalgia with formula acupuncture: investigation of needle placement, needle stimulation, and treatment frequency. J Altern Complement Med. 2005;11(4):663-71.

62. Assefi NP, Sherman KJ, Jacobsen C, Goldberg J, Smith WR, Buchwald DA randomized clinical trial of acupuncture compared with sham acupuncture in fibromyalgia. Ann Intern Med. 2005;143(1):109.

63. Harris RE, Zubieta JK, Scott DJ, Napadow V, Gracely RH, Clauw DJ. Traditional Chinese acupuncture and placebo (sham) acupuncture are differentiated by their effects on mu-opioid receptors (MORs). Neuroimage.2009;47(3):1077-85. 
64. Dias, P. A. Efeitos da acupuntura, eletroacupuntura e moxabustão na qualidade de vida e no controle da dor em mulheres fibromiálgicas (dissertação). Fortaleza: Universidade Federal do Ceará; 2012.

65. Vas J, Modesto M, Aguilar I, SantosRey K, Benítez-Parejo N, Rivas-Ruiz F. Effects of acupuncture on patients with fibromyalgia: study protocol of a multicentre randomized controlled trial. Trials. 2016;12(59).

66. Martin DP, Sletten CD, Williams BA, Berger IH. Improvement in Fibromyalgia Symptoms With Acupuncture: Results of a Randomized Controlled Trial. Mayo Clin Proc. 2006;81(6):749-57.

67. Targino RA, Imamura M, Kaziyama HH, Souza LP, Hsing WT, Furlan AD, et al. A randomized controlled trial of acupuncture added to usual treatment for fibromyalgia. J Rehabil Med. 2010;40(7):582-88.

68. Araujo RAT. Tratamento da dor na fibromialgia com acupuntura (tese). São Paulo: Universidade de São Paulo; 2007.

69. Oliveira SG, Ourique AAB, Macuco MIB. Acupuntura: Melhorando a qualidade de vida das mulheres com fibromialgia. Ciência, Cuidado e Saúde. 2008;7(1):1-4.

70. Lemos TV, Olsson DS, Carrijo D. Acupuntura na fibromialgia: Um estudo de caso. Revista Brasileira de Fisioterapia. 2006;10(1):88-89.

71. Mendonça CM. Eficácia da acupuntura sobre a dor e a qualidade de vida em mulheres com fibromialgia. Revista PIBIC. 2006;3(1):75-81.

72. Itoh K, Kitakoji H. Effects of acupuncture to treat fibromyalgia: A preliminary randomised controlled trial. Chinese Medicine. 2010;5(11).

73. Sprott H, Franke S, Kluge H, Hein G. Pain treatment of fibromyalgia by acupuncture. Rheumatol Int. 1998;18(1):35-6.

74. Chao EC. Efectividad de la acupuntura en el alivio del dolor refractario al tratamiento farmacológico convencional. Rev Soc Esp Dolor. 2009;16(2):79-86.

75. Hong JP. Acupuntura: De terapia alternativa a especialidade médica. São Paulo: Ed. Ceimec; 2005.

76. Dias MHP, Amaral E, Pai HJ, Tsai DTY, Lotito APN, Leone C, et al. Acupuntura em adolescentes com fibromialgia juvenil. Rev. Paul. Pediatr. 2002;30(1):34-45.

77. Ma YT, Ma M, Cho ZH. Acupuntura para controle da dor: um enfoque integrado. São Paulo: Roca; 2006.

78. Christ CD. Acupuntura e dor crônica. Revista dor. 2006;7(1):1-6.

79. Kaptchuk TJ. Acupuncture: theory, efficacy, and practice. Ann Intern Med. 2002;136(5):374-83.

80. Medeiros R, Saad M. Acupuntura: efeitos fisiológicos além do efeito placebo. O Mundo da Saúde. São Paulo. 2009;33(1):69-72.

Data de submissão: 28/11/2019

Data de aprovação: 16/12/2019 